Check for updates

Cite this: RSC Adv., 2017, 7, 43474

Received 13th June 2017

Accepted 4th September 2017

DOI: $10.1039 / c 7 r a 06592 b$

rsc.li/rsc-advances

\section{Self-assembly of biosurfactant-inorganic hybrid nanoflowers as efficient catalysts for degradation of cationic dyes $\uparrow$}

\author{
Jianmei Jiao, ${ }^{a}$ Xia Xin, (D) *ab Xingang Wang, ${ }^{\mathrm{C}}$ Zengchun Xie, ${ }^{\mathrm{a}}$ Congxin $\mathrm{Xia}^{\mathrm{a}}$ \\ and Wei Pan ${ }^{d}$
}

\begin{abstract}
Three-dimensional (3D) hierarchical nanostructures have generated a large amount of interest because of their unique, unusual properties and potential applications. In this article, copper(II) ions as the inorganic component and various biosurfactants as the organic component were used to successfully form 3D nanoflowers via a facile and effective self-assembly template synthesis strategy. It can be confirmed that the biosurfactant molecules can first form complexes with the copper ions, and these complexes then become nucleation sites for primary crystals of copper phosphate, indicating that the interaction between biosurfactant and copper ions leads to the formation of 3D nanoflowers. Several reaction parameters such as aging time and the concentration of the biosurfactant, which play a critical role in the formation process and morphologies of the nanoflowers, were investigated. Under the optimum synthetic conditions, a spherical flowerlike structure with hundreds of nanopetals was obtained. Moreover, the biosurfactant- $\mathrm{Cu}_{3}\left(\mathrm{PO}_{4}\right)_{2} \cdot 3 \mathrm{H}_{2} \mathrm{O}$ nanoflowers also showed high stability and catalytic activity for degradation of cationic dyes. Our results demonstrate that the biosurfactant-inorganic 3D nanoflowers, which combined the advantages of the biosurfactant and inorganic material, have potential applications in industrial biocatalysis, biosensors, and environmental chemistry.
\end{abstract}

\section{Introduction}

Nano-structured materials have attracted increasing attention in recent years and great contributions have been made in the morphology-controlled synthesis of micro- and nano-scale structures, such as nanodendrites, core/shell nanoparticles, nanowires, and nanoflowers. ${ }^{1-5}$ Among them, "nanoflower" is a fantastic name for some of the nanomaterials whose microscopic images resemble flowers. A variety of materials such as carbon, ${ }^{6-8}$ metals and other elemental materials, ${ }^{9-11}$ alloys, ${ }^{12,13}$ and metaloxides/hydroxides ${ }^{14}$ have been widely reported to form flower-like structure. ${ }^{15,16}$ Due to the large surface-tovolume ratio compared with that of bulk materials, these nanoflowers have many applications in catalysis, magnetism, nanodevices, sensing and biosensing and medicine. ${ }^{17-24}$ But

${ }^{a}$ National Engineering Technology Research Center for Colloidal Materials, Shandong University, Shanda Nanlu No.27, Jinan, 250100, P. R. China. E-mail: xinx@sdu.edu. cn; Fax: +86-531-88361008; Tel: +86-531-88363597

${ }^{b}$ State Key Laboratory of Solid Lubrication, Lanzhou Institute of Chemical Physics, Chinese Academy of Sciences, Lanzhou, Gansu Province 730000, China

'China Research Institute of Daily Chemical Industry, Taiyuan, Shanxi, 030001, P. R. China

${ }^{d}$ College of Chemistry, Chemical Engineering and Materials Science, Shandong Normal University, Jinan 250014, P. R. China

$\dagger$ Electronic supplementary information (ESI) available. See DOI: $10.1039 / \mathrm{c} 7 \mathrm{ra06592b}$ nanoflowers are traditionally synthesized under harsh conditions such as high temperature, pressure and the use of toxic organic solvents. Thus, it is still a challenge to explore a low cost and facile synthetic method for the preparation of hierarchical nanoflowers.

Gratifyingly, self-assembly can spontaneously combine different components together to form different kinds of hybrid materials, ${ }^{25}$ while the template synthesis is an effective approach to synthetize nanomaterials with various morphologies. ${ }^{26}$ Thus, a self-assembled template synthesis provides a facile and effective low temperature synthetic strategy for the fabrication of well-defined nanoflowers. Especially, the bioinspired materials with micro- and nano-scale have been proposed as a big breakthrough on the design of functional materials due to the huge advantage of the bio-molecules in directing and assembling the nanoflowers. ${ }^{27-30}$ Various biomolecules, such as enzyme, ${ }^{31-36}$ protein, ${ }^{37}$ amino acids ${ }^{38}$ have been applied to synthesis nanoflower. For example, Zare's group reported the novel synthesis of hybrid nanoflowers comprising of $\mathrm{Cu}_{3}\left(\mathrm{PO}_{4}\right)_{2}$ and proteins for the first time and they also synthetized immobilized enzymes with greatly enhanced activities. ${ }^{39}$ Subsequently, using the same synthetic route, Wang et al. prepared $\mathrm{CaHPO}_{4}-\alpha$-amylase nanoflowers and they also further elaborated the mechanism for enhanced catalytic activity of immobilized enzyme. ${ }^{40}$ Although biodegradable amphiphilic molecules have been widely used in the fabrication of 
nanomaterials ${ }^{41,42}$ and self-assembly process assisted by amphiphilic molecules can provide a powerful low temperature tool for the synthesis of hierarchical structures, ${ }^{43}$ the usage of bio-surfactants in the fabrication of nanoflower has not been reported so frequently.

In this paper, a facile and effective self-assembled template synthesis strategy for shape controlled synthesis of threedimensional (3D) flower-like $\mathrm{Cu}_{3}\left(\mathrm{PO}_{4}\right)_{2} \cdot 3 \mathrm{H}_{2} \mathrm{O}$ microstructures were provided using copper(II) ions as the inorganic component and various biosurfactants as the organic component. The hybrid nanoflowers were fully characterized by transmission electron microscopy (TEM), field emission scanning electron microscopy (FE-SEM), Fourier transform infrared (FT-IR) spectroscopy and X-ray diffraction (XRD). Different growth stages and concentration of biosurfactants on the effect of the morphologies of hybrid nanoflowers were intensively identified and studied. The synthesized biosurfactant- $\mathrm{Cu}_{3}\left(\mathrm{PO}_{4}\right)_{2} \cdot 3 \mathrm{H}_{2} \mathrm{O}$ hybrid nanoflowers exhibited high stability and catalytic activity for degradation of cationic dyes. Moreover, the catalyst for MB can be recycled and reused at least six cycles with only a slight dropping of catalytic efficiency, suggesting their promising applications in the treatment of waste water.

\section{Experimental}

\section{Reagents and materials}

Sodium cholate (SC), sodium deoxycholate (SDC), sodium dihydrogen phosphate $\left(\mathrm{NaH}_{2} \mathrm{PO}_{4} \cdot 2 \mathrm{H}_{2} \mathrm{O}\right)$ and disodium phosphate dodecahydrate $\left(\mathrm{Na}_{2} \mathrm{HPO}_{4} \cdot 12 \mathrm{H}_{2} \mathrm{O}\right)$ were obtained from Sinopharm Chemical Reagent, Co., Ltd (Shanghai, China). Copper sulfate pentahydrate $\left(\mathrm{CuSO}_{4} \cdot 5 \mathrm{H}_{2} \mathrm{O}\right)$ was purchased from Fuchen Chemical Reagent Factory (Tianjin, China). Polypeptide GG-4 were the products of GL Biochem, Co., Ltd (Shanghai, China) and Meilunbio, Co., Ltd (Dalian, China), respectively. Rhodamine B (RhB), rhodamine 6G (R6G) and methylene blue (MB) were purchased from Kermel Chemical Reagent, Co., Ltd (Tianjin, China). The structures of SC, SDC, GG-4 and RhB, R6G, MB were shown in Fig. S1. $\dagger$ All other chemicals were of analytical grade or better. Ultrapure water with a resistivity of $18.25 \mathrm{M} \Omega \mathrm{cm}$ was obtained using a UPH-IV ultrapure water purifier (China).

\section{Synthesis of biosurfactant-inorganic nanoflowers}

Biosurfactant- $\mathrm{Cu}_{3}\left(\mathrm{PO}_{4}\right)_{2}$ nanoflowers were synthesized similar to the previous literature. ${ }^{25}$ Briefly, $20 \mu \mathrm{L}$ of aqueous $\mathrm{CuSO}_{4}$ $\cdot 5 \mathrm{H}_{2} \mathrm{O}$ solution $(120 \mathrm{mM})$ was added into $3 \mathrm{~mL}$ of phosphate buffered saline (PBS) solution (2 mM, pH 7.4) with different concentrations of biosurfactants. The solution was incubation at room temperature for $72 \mathrm{~h}$ and the obtained blue products were washed with water for three times, centrifuged at $7000 \mathrm{rpm}$ for $5 \mathrm{~min}$ and then dried at room temperature.

\section{Characterization of biosurfactant-inorganic nanoflowers}

Transmission electron microscopy (TEM) observations were carried out on a JEM-100 CXII (JEOL) at an accelerating voltage of $80 \mathrm{kV}$. For sample preparation, the obtained powder was placed on a ultrathin carbon-coated copper grid and the excess powder was wicked away with filter paper, which was then dried by using a near infrared reflection (NIR) lamp before observations. Field-emission scanning electron microscopy (FE-SEM) observations were carried out on SU8010 (HATACHI), a drop of wet powder was placed on a silica wafer to form a thin film then dried by using NIR lamp. Energy-Dispersive X-ray Spectroscopy (EDS) analysis and telemental mapping were also performed on the same FE-SEM microscope. FT-IR spectra were recorded 4000 to $400 \mathrm{~cm}^{-1}$ on a VERTEX-70/70v spectrometer (Bruker Optics, Germany). The samples for FT-IR spectra were prepared by using $\mathrm{KBr}$ pellets mixed with the powder we obtained. XRD patterns of the samples were obtained between 10 and 90 in the $2 \theta$ scan mode $\left(2.5 \mathrm{~min}^{-1}\right)$ using a Rigaku D/Max $2200 \mathrm{PC}$ diffractometer with $\mathrm{Cu} \mathrm{K} \alpha$ radiation $(\lambda=0.15418$ $\mathrm{nm}$ ) and a graphite monochromator at room temperature. UVvis measurements were carried out on a computer manipulated spectrometer (UV-vis 4100, Hitachi, Japan).

\section{Degradation of cationic dyes}

Three cationic dyes RhB, R6G and MB were chosen as samples to investigate the catalytic activity of our nanoflowers for degradation of cationic dyes by $\mathrm{H}_{2} \mathrm{O}_{2}$. The initial concentration of dye solutions were $12.5 \mu \mathrm{g} \mathrm{mL}^{-1}$, concentration of dye solutions during degradation were detected by UV-vis measurements. The degradation rates were calculated using the following equation:

$$
\mathrm{DR}=\frac{C_{0}-C_{t}}{C_{0}} \times 100 \%
$$

where $C_{0}$ and $C_{t}$ are initial concentration and concentration at time $t$.

\section{Results and discussion}

\section{Microstructures of biosurfactant-inorganic nanoflowers}

Xie's group have reported the biomolecule-assisted synthesis of $\mathrm{Bi}_{2} \mathrm{~S}_{3}$ flowerlike patterns which need a relatively high reaction temperature $\left(150{ }^{\circ} \mathrm{C}\right) .{ }^{44}$ However, in our experiment, the biosurfactant-inorganic nanoflowers were prepared by a facile and efficient low temperature (at room temperature) process by using $\mathrm{CuSO}_{4} \cdot 5 \mathrm{H}_{2} \mathrm{O}$ as the precursor, and biosurfactants as the assistant of the formation of 3D flower-like microstructures. To validate our design, $\mathrm{SC}-\mathrm{Cu}_{3}\left(\mathrm{PO}_{4}\right)_{2} \cdot 3 \mathrm{H}_{2} \mathrm{O}$ nanoflowers were firstly prepared. Blue precipitates were formed after 3 days incubation and TEM images shows that the nanoflower morphologies were formed (Fig. 1A-C). SEM images further confirmed the flower-like morphology (Fig. 1D-F) and it can be observed that the samples consist of large quantities of flowerlike nanostructures with diameters in the range of 15-30 $\mu \mathrm{m}$ which possess high surface-to-volume ratios and have good monodispersity. Subsequently, the elemental mapping (Fig. 2) and EDS pattern (Fig. S2 $\dagger$ ) further confirm that $\mathrm{C}, \mathrm{Na}, \mathrm{Cu}, \mathrm{P}$ and $\mathrm{O}$ elements are homogeneously distributed inside the nanoflowers which gave a proof that the nanoflowers obtained were complex of $\mathrm{SC}$ and $\mathrm{Cu}_{3}\left(\mathrm{PO}_{4}\right)_{2} \cdot 3 \mathrm{H}_{2} \mathrm{O}$. When $\mathrm{SC}$ was replaced by 

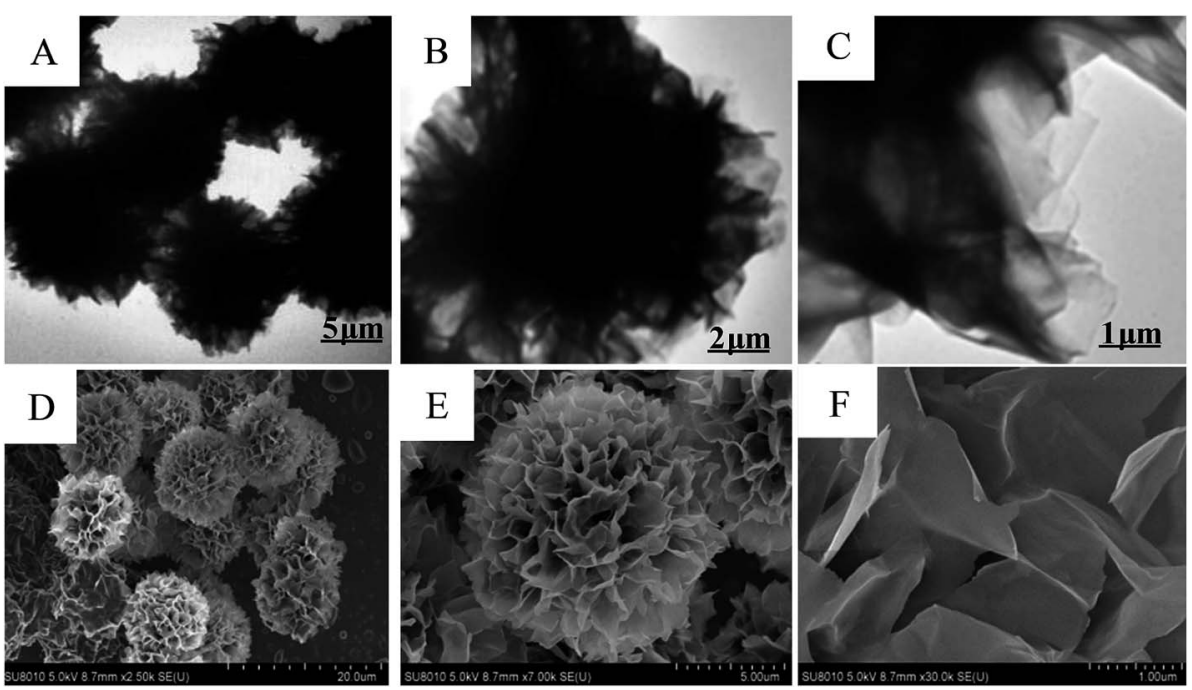

Fig. 1 The detailed characterizations of $\mathrm{SC}-\mathrm{Cu}_{3}\left(\mathrm{PO}_{4}\right)_{2} \cdot 3 \mathrm{H}_{2} \mathrm{O}$ nanoflowers $\left(0.1 \mathrm{mg} \mathrm{mL}^{-1} \mathrm{SC}\right)$. TEM image of (A) hybrid nanoflowers, (B) a local partial enlarged image of (A), and (C) nanopetals (a local partial enlarged image of (B)). SEM images of (D) hybrid nanoflowers, (E) single nanoflower (a local partial enlarged image of $(D))$ and $(F)$ nanopetals (a local partial enlarged image of (E)).
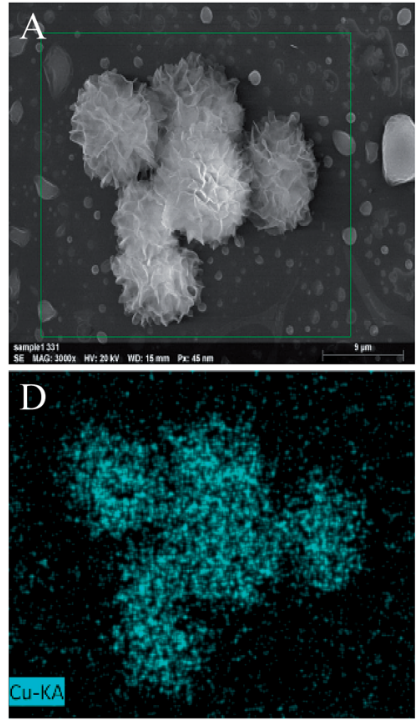
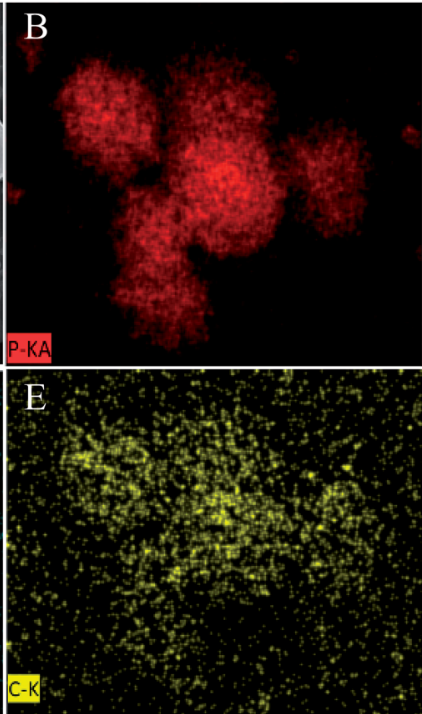

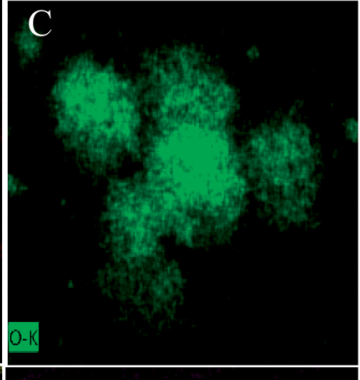

F

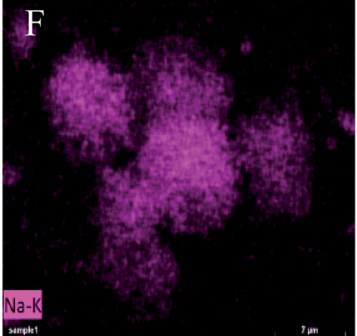

Fig. 2 (A) SEM image of $\mathrm{SC}-\mathrm{Cu}_{3}\left(\mathrm{PO}_{4}\right)_{2} \cdot 3 \mathrm{H}_{2} \mathrm{O}$ nanoflowers. SEM element mapping analyses of nanoflowers: (B) P, (C) O, (D) Cu, (E) C, (F) Na.

other two biosurfactants SDC and GG-4, flower-like microstructures were also been found as shown in Fig. S3 (ESI $\dagger$ ). We have calculated the surface area and as $3.20 \mathrm{~m}^{2} \mathrm{~g}^{-1}$ and an average pore size of $3.23 \mathrm{~nm}$ through BET measurement (Fig. S4†).

\section{FT-IR and XRD analysis}

FT-IR spectroscopy directly confirms the formation of $3 \mathrm{D}$ nanoflowers. In the spectrum of $\mathrm{Cu}_{3}\left(\mathrm{PO}_{4}\right)_{2} \cdot 3 \mathrm{H}_{2} \mathrm{O}$ and $\mathrm{SC}-$ $\mathrm{Cu}_{3}\left(\mathrm{PO}_{4}\right)_{2} \cdot 3 \mathrm{H}_{2} \mathrm{O}$ nanoflowers (Fig. 3A), the peaks at 1054 and $1150 \mathrm{~cm}^{-1}$ were attributed to $\mathrm{P}-\mathrm{O}$ and $\mathrm{P}=\mathrm{O}$ vibrations, ${ }^{36}$ while the bands at 566 and $603 \mathrm{~cm}^{-1}$ were attributed to the bending vibrations of bridging phosphorous such as $\mathrm{O}=\mathrm{P}-\mathrm{O}$ which indicated the existence of phosphate groups. ${ }^{35}$ The weak peak at $1620 \mathrm{~cm}^{-1}$ came from the crystal water in $\mathrm{Cu}_{3}\left(\mathrm{PO}_{4}\right)_{2} \cdot 3 \mathrm{H}_{2} \mathrm{O}$. Compared to the spectrum of $\mathrm{Cu}_{3}\left(\mathrm{PO}_{4}\right)_{2} \cdot 3 \mathrm{H}_{2} \mathrm{O}$, the typical bands of SC at $2800-3000 \mathrm{~cm}^{-1}$ for $-\mathrm{CH}_{2}$ and $-\mathrm{CH}_{3}$ were also observed in the spectrum of $\mathrm{SC}-\mathrm{Cu}_{3}\left(\mathrm{PO}_{4}\right)_{2} \cdot 3 \mathrm{H}_{2} \mathrm{O}$ nanoflowers, indicating the presence of SC component in the hybrid material. Moreover, the spectrum of hybrid nanoflowers didn't show significant shift of the peaks or any new adsorption peaks, indicating the hybrid nanoflowers formed via self-assembly instead of covalent bonding.

XRD analysis (Fig. 3B and the inset) were performed to further confirm the crystallinity of the nanoflowers. It can be seen that the positions and intensities of the diffraction peaks of $\mathrm{Cu}_{3}\left(\mathrm{PO}_{4}\right)_{2} \cdot 3 \mathrm{H}_{2} \mathrm{O}$ are consistent with those obtained from the 

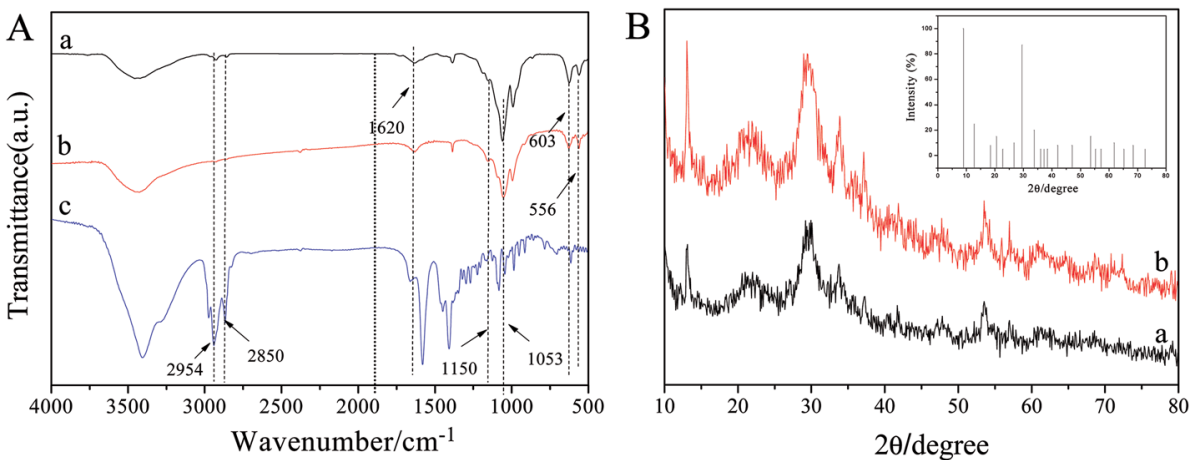

Fig. 3 (A) FT-IR spectra of (a) $\mathrm{SC}-\mathrm{Cu}_{3}\left(\mathrm{PO}_{4}\right)_{2} \cdot 3 \mathrm{H}_{2} \mathrm{O}$ nanoflowers; (b) $\mathrm{Cu}_{3}\left(\mathrm{PO}_{4}\right)_{2}$; (c) $\mathrm{SC}$; (B) XRD patterns of (a) $\mathrm{Cu}_{3}\left(\mathrm{PO}_{4}\right)_{2}$ and (b) $\mathrm{SC}-\mathrm{Cu}_{3}(-$ $\left.\mathrm{PO}_{4}\right)_{2} \cdot 3 \mathrm{H}_{2} \mathrm{O}$ nanoflowers, inset is the standard card of $\mathrm{Cu}_{3}\left(\mathrm{PO}_{4}\right)_{2} \cdot 3 \mathrm{H}_{2} \mathrm{O}(\mathrm{JPSCD00}-022-0548)$.

JCPDS card (00-022-0548). Thus, it can be concluded that even after incorporating $\mathrm{SC}$, the $\mathrm{SC}-\mathrm{Cu}_{3}\left(\mathrm{PO}_{4}\right)_{2} \cdot 3 \mathrm{H}_{2} \mathrm{O}$ nanoflowers were still well crystallized. ${ }^{33}$

Effects of the dosage of SC on the morphologies of SC$\mathrm{Cu}_{3}\left(\mathrm{PO}_{4}\right)_{2} \cdot 3 \mathrm{H}_{2} \mathrm{O}$ nanoflowers

In order to explore the effect of the dosage of biosurfactants on the morphologies of $\mathrm{SC}-\mathrm{Cu}_{3}\left(\mathrm{PO}_{4}\right)_{2} \cdot 3 \mathrm{H}_{2} \mathrm{O}$ nanoflowers, the concentrations of SC which ranged from 0 to $0.5 \mathrm{mg} \mathrm{mL}^{-1}$ were first investigated as a sample. As shown in Fig. 4, in the absence of SC, large amorphous crystals of $\mathrm{Cu}_{3}\left(\mathrm{PO}_{4}\right)_{2} \cdot 3 \mathrm{H}_{2} \mathrm{O}$, but no nanoflowers were formed (Fig. $4 \mathrm{~A}_{1}$ and $\mathrm{A}_{2}$ ). However, when SC was added, the flower-like nanostructures emerged. When the concentration of SC was $0.05 \mathrm{mg} \mathrm{mL}^{-1}$, there were many slices that resembled the petals of flowers with rough fringes (Fig. 4B ${ }_{1}$ ). Besides, some nanoflowers with an average size of $\sim 20 \mu \mathrm{m}$ were also formed in this concentration (Fig. $4 \mathrm{~B}_{2}$ ). With the increase of SC concentration from 0.05 to $0.1 \mathrm{mg} \mathrm{mL}^{-1}$, the petal-like structure gradually formed flowerlike structure
(Fig. $4 \mathrm{C}_{1}$ and $\mathrm{C}_{2}$ ), while the average size of the nanoflowers decrease from $\sim 20 \mu \mathrm{m}$ to $\sim 15 \mu \mathrm{m}$ when SC concentration increased to $0.5 \mathrm{mg} \mathrm{mL}^{-1}$ (Fig. $4 \mathrm{D}_{1}$ and $\mathrm{D}_{2}$ ). The decrease of the average size of the nanoflowers may be attribute to the steric hindrance's enhancement with increase the SC molecules attached to $\mathrm{Cu}_{3}\left(\mathrm{PO}_{4}\right)_{2} \cdot 3 \mathrm{H}_{2} \mathrm{O}$ crystal nucleus. The results demonstrated that SC worked as the size- and shape-controlling agent in the synthesis process and the sizes of the nanoflowers were strongly dependent on SC concentration. ${ }^{33,36}$

\section{Effects of the growth time on the morphologies of SC- $\mathrm{Cu}_{3}\left(\mathrm{PO}_{4}\right)_{2} \cdot 3 \mathrm{H}_{2} \mathrm{O}$ nanoflowers}

In order to get more information about the growth mechanism of $\mathrm{SC}-\mathrm{Cu}_{3}\left(\mathrm{PO}_{4}\right)_{2} \cdot 3 \mathrm{H}_{2} \mathrm{O}$ nanoflowers, the morphologies of the hybrid materials were recorded by SEM images as a function of the growth time of the nanoflowers. The experiments were carried out in identical concentrations but for different incubation time (1, 3, 6, 12 and $15 \mathrm{~h})$ and the SEM images shown in Fig. 4 suggest a progressive process of nanoflower assembly. It
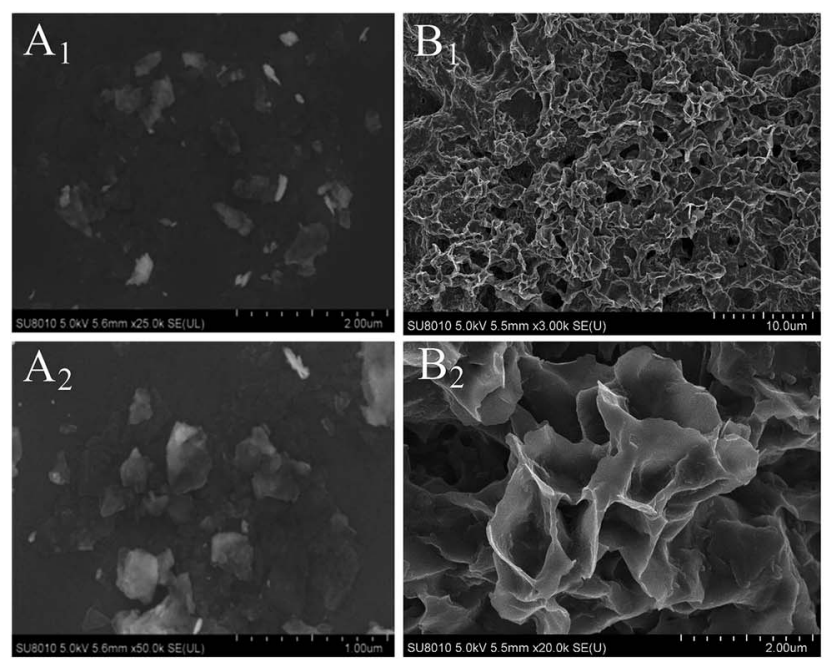
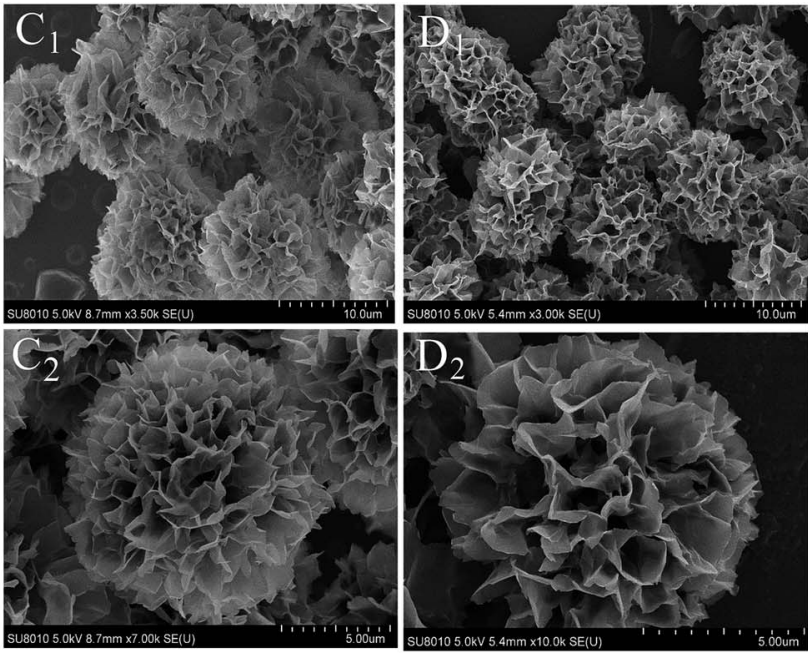

Fig. 4 Effect of different concentrations of $\mathrm{SC}$ on the morphologies of $\mathrm{SC}-\mathrm{Cu}_{3}\left(\mathrm{PO}_{4}\right)_{2} \cdot 3 \mathrm{H}_{2} \mathrm{O}$ nanoflowers hybrid nanoflowers. $\left(\mathrm{A}_{1}\right.$, $\left.\mathrm{A}_{2}\right)$ $0 \mathrm{mg} \mathrm{mL}^{-1} ;\left(B_{1}, B_{2}\right) 0.05 \mathrm{mg} \mathrm{mL}^{-1} ;\left(C_{1}, C_{2}\right) 0.1 \mathrm{mg} \mathrm{mL}^{-1} ;\left(D_{1}, D_{2}\right) 0.5 \mathrm{mg} \mathrm{mL}^{-1}$. $\left(A_{2}, B_{2}, C_{2}\right.$ and $\left.D_{2}\right)$ are the local partial enlarged images of $\left(A_{1}, B_{1}, C_{1}\right.$ and $\mathrm{D}_{1}$ ), respectively. Other conditions: $120 \mathrm{mmol} \mathrm{L}{ }^{-1} \mathrm{Cu}^{2+}, 0.1 \mathrm{~mol} \mathrm{~L}{ }^{-1} \mathrm{PBS}$ at $\mathrm{pH}=7.4$, and reaction for $72 \mathrm{~h}$ at $25^{\circ} \mathrm{C}$. 
can be observed that the blue precipitates can be obtained as soon as the addition of $\mathrm{CuSO}_{4} \cdot 5 \mathrm{H}_{2} \mathrm{O}$ solution to PBS solution which contains SC. At an early growth stage $(1 \mathrm{~h})$, both primary crystals of $\mathrm{Cu}_{3}\left(\mathrm{PO}_{4}\right)_{2} \cdot 3 \mathrm{H}_{2} \mathrm{O}$ and copper-cholate complexes which formed mainly through coordination between carboxyl groups in the SC backbone and $\mathrm{Cu}^{2+}$ were appeared. ${ }^{41-43}$ Moreover, these complexes can provide a location for nucleation of the primary crystals of $\mathrm{Cu}_{3}\left(\mathrm{PO}_{4}\right)_{2} \cdot 3 \mathrm{H}_{2} \mathrm{O}$ (Fig. $5 \mathrm{~A}_{1}$ and $\mathrm{A}_{2}$ ). When the reaction time reached to $3 \mathrm{~h}$ (Fig. $5 \mathrm{~B}_{1}$ and $\mathrm{B}_{2}$ ), the coppercholate complexes combined into large agglomerates. Subsequently, the kinetically controlled growth of $\mathrm{Cu}_{3}\left(\mathrm{PO}_{4}\right)_{2} \cdot 3 \mathrm{H}_{2} \mathrm{O}$ crystals occured on the surface of these agglomerates. As time sequentially increased to 6-12 h, anisotropic growth of these crystals led to the formation of flower-like structure (Fig. 5C1, $\mathrm{C} 2, \mathrm{D} 1$ and $\mathrm{D} 2)$. When the reaction time reached $15 \mathrm{~h}$, a branched flower-like structure completely formed (Fig. $5 \mathrm{E}_{1}$ and $\mathrm{E}_{2}$ ). That is to say, in this growth process, $\mathrm{SC}$ induced the nucleation of the $\mathrm{Cu}_{3}\left(\mathrm{PO}_{4}\right)_{2} \cdot 3 \mathrm{H}_{2} \mathrm{O}$ crystals to form the scaffold for the petals, and also served as a "glue" to bind the petals together. ${ }^{33}$ Based on the experimental results, the formation mechanism of $\mathrm{SC}-\mathrm{Cu}_{3}\left(\mathrm{PO}_{4}\right)_{2} \cdot 3 \mathrm{H}_{2} \mathrm{O}$ flowerlike structures as a function of the growth time was shown in Scheme 1.

\section{Catalytic behaviors for the degradation of cationic dyes}

It's known that copper compound possess intrinsic peroxidaselike activity in the presence of $\mathrm{H}_{2} \mathrm{O}_{2} \cdot{ }^{44-46}$ Therefore, the peroxidase-like activities of the copper-cholate complexes in biosurfactant-incorporated nanoflowers were investigated. Three cationic dyes RhB, R6G and MB (structures of the three dyes were shown in Fig. $\mathrm{S} 1 \dagger$ ) were chosen to investigate the peroxidase-like activity of $\mathrm{SC}-\mathrm{Cu}_{3}\left(\mathrm{PO}_{4}\right)_{2} \cdot 3 \mathrm{H}_{2} \mathrm{O}$ nanoflowers. Firstly, the concentration of each dye detected by UV-vis absorption at different time points during the degradation process were measured and the results were shown in Fig. 5. It can be seen that a visual color change of cationic dyes solution $\left(12.5 \mu \mathrm{g} \mathrm{mL}{ }^{-1}\right)$ occured only when $\mathrm{H}_{2} \mathrm{O}_{2}$ and nanoflowers were co-existence which indicated that the $\mathrm{SC}-\mathrm{Cu}_{3}\left(\mathrm{PO}_{4}\right)_{2} \cdot 3 \mathrm{H}_{2} \mathrm{O}$

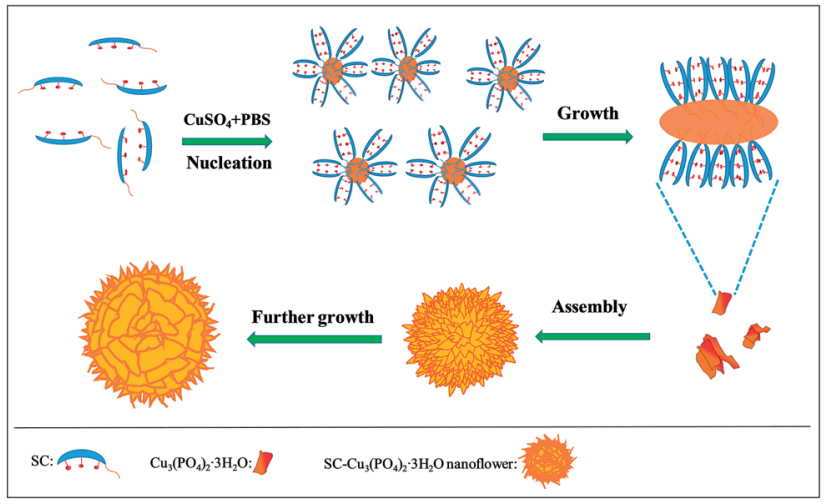

Scheme 1 The formation mechanism of $\mathrm{SC}-\mathrm{Cu}_{3}\left(\mathrm{PO}_{4}\right)_{2} \cdot 3 \mathrm{H}_{2} \mathrm{O}$ flowerlike structures as a function of the growth time.

nanoflower had degraded all the three dyes dramatically and exhibited excellent catalytic activities for cationic dyes degradation reaction in the presence of $\mathrm{H}_{2} \mathrm{O}_{2}$ (Fig. $6 \mathrm{~A}-\mathrm{C}$ and $\mathrm{S} 5 \dagger$ ). The morphology of nanoflower after degradation had also been investigated, as is shown in Fig. S6, $\uparrow$ it can be seen that after the degradation of dyes, partial nanoflowers had disaggregated into nanoplates.

Meanwhile, in order to trace the degradation process, the changing concentrations of cationic dyes solutions over time were detected by UV-vis (Fig. S5A-C $\dagger$ ). The comparison of degradation rates for different dyes shown in Fig. S5D $\uparrow$ revealed that at the first stage $(1 \mathrm{~h})$, the degradation rates were $\mathrm{MB}>\mathrm{RhB}$ $>$ R6G. Subsequently the degradation rate of RhB increased, while $\mathrm{MB}$ and R6G were both degraded with a lower speed. In general, R6G had the lowest degradation rate, MB performed the highest degradation speed. The linear fit of the $\ln \left(C_{t} / C_{0}\right)$ data reveals that the catalytic reaction exhibits pseudo-firstorder kinetics for the degradation of the three dyes (Fig. S7 $\dagger$ ). The rate constant $k$ of the oxidation reaction was determined to be $0.89,0.25$ and $0.22 \mathrm{~h}^{-1}$, corresponding to $\mathrm{MB}$, RhB and R6G respectively, based on eqn (1) and (2). The degradation rate for the three dyes are $\mathrm{MB}>\mathrm{RhB}>\mathrm{R} 6 \mathrm{G}$.
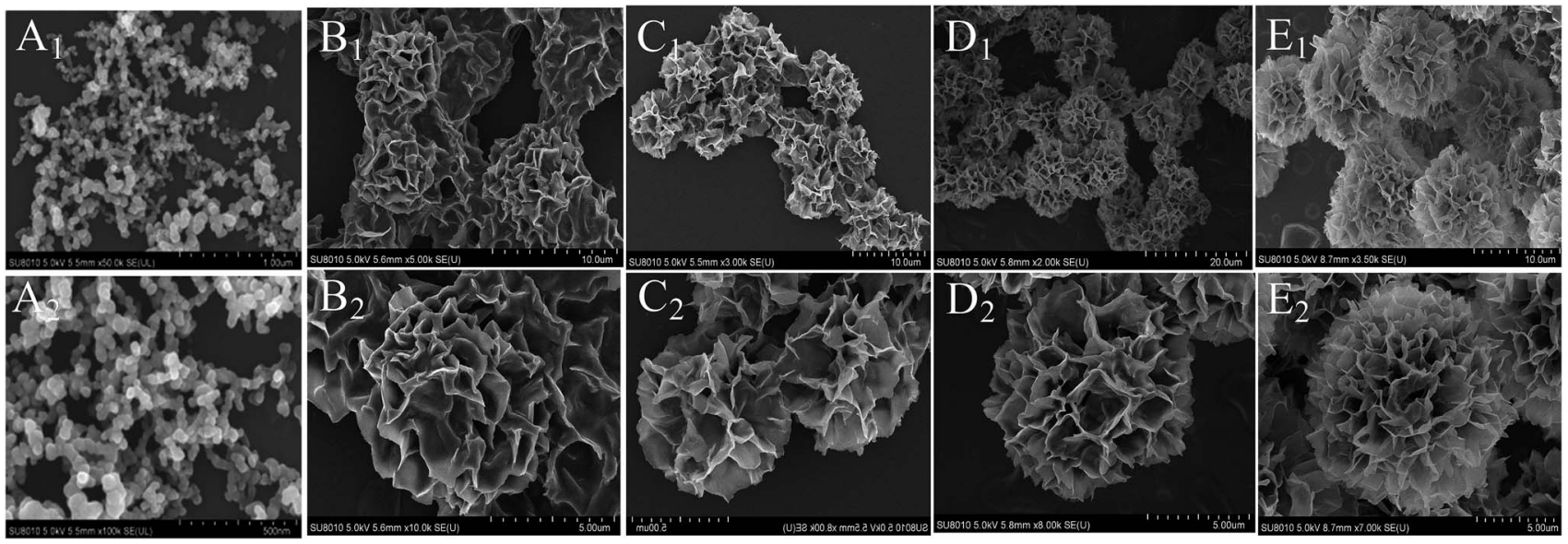

Fig. 5 Effect of different growth time on the morphologies of $S C-C_{3}\left(P O_{4}\right)_{2} \cdot 3 H_{2} O$ nanoflowers. $\left(A_{1}, A_{2}\right) 1 \mathrm{~h} ;\left(B_{1}, B_{2}\right) 3 h ;\left(C_{1}, C_{2}\right) 6 h ;\left(D_{1}, D_{2}\right) 12$; $\left(E_{1}, E_{2}\right) 15 \mathrm{~h} .\left(A_{2}, B_{2}, C_{2}, D_{2}\right.$ and $\left.E_{2}\right)$ are the local partial enlarged images of $\left(A_{1}, B_{1}, C_{1}, D_{1}\right.$ and $\left.E_{1}\right)$, respectively. These series of experiments were carried out in identical concentrations: $120 \mathrm{mmol} \mathrm{L}^{-1} \mathrm{Cu}^{2+}, 0.1 \mathrm{~mol} \mathrm{~L}{ }^{-1} \mathrm{PBS}$ at $\mathrm{pH} 7.4,0.1 \mathrm{mg} \mathrm{mL}^{-1} \mathrm{SC}$, and reaction at $25{ }^{\circ} \mathrm{C}$. 

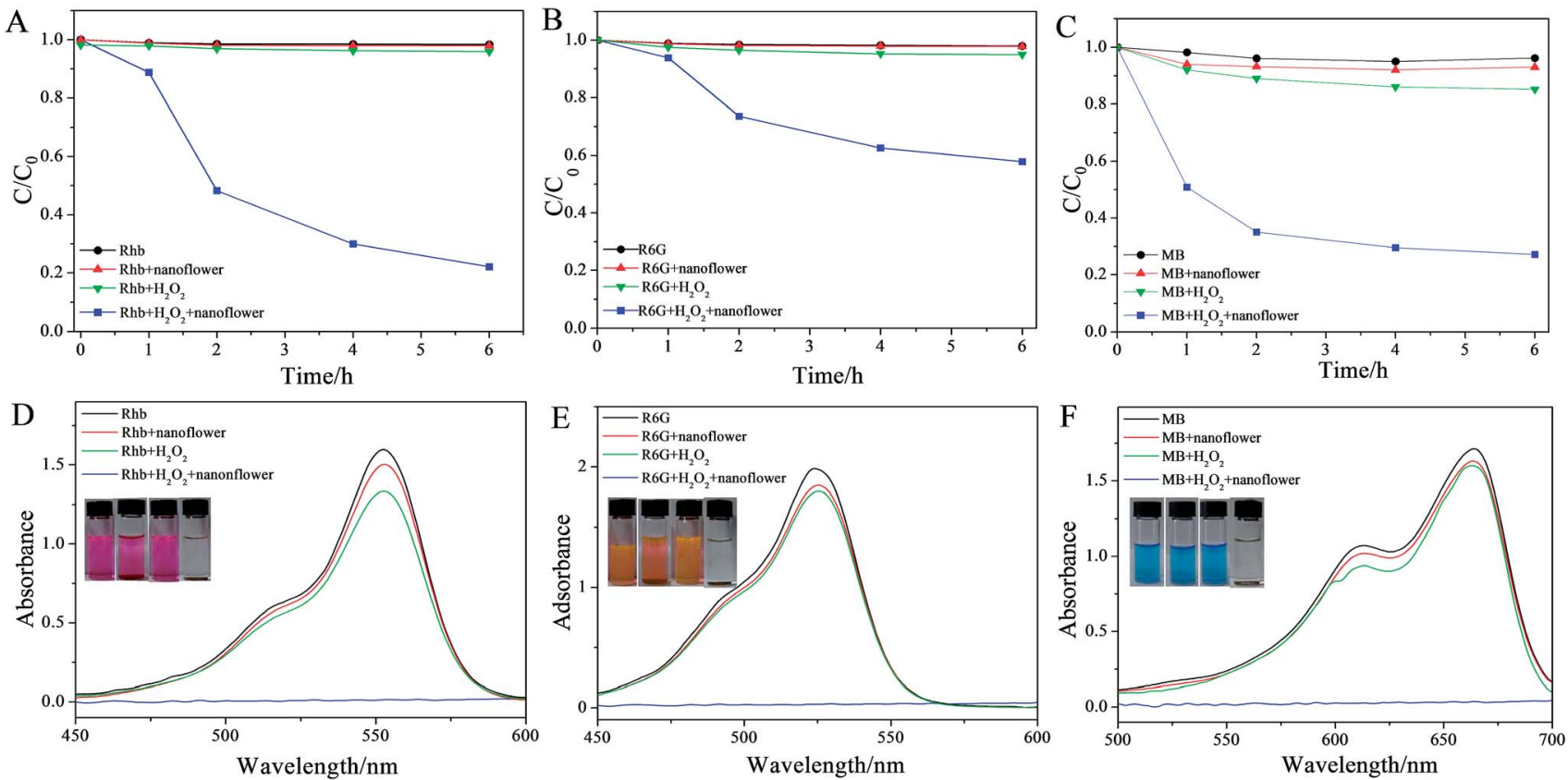

Fig. 6 Catalytic activity of $\mathrm{SC}-\mathrm{Cu}_{3}\left(\mathrm{PO}_{4}\right)_{2} \cdot 3 \mathrm{H}_{2} \mathrm{O}$ nanoflower for degradation of (A) RhB; (B) R6G; (C) MB, and UV-vis spectrum of (D) RhB; (E) R6G; (F) MB. Inset photos were the color changes of cationic dyes solutions (from left to right): blank control (12.5 $\mu \mathrm{g} \mathrm{mL} \mathrm{m}^{-1} \mathrm{dye} \mathrm{solutions),} 125 \mu \mathrm{g} \mathrm{mL} \mathrm{L}^{-1}$ $\mathrm{SC}-\mathrm{Cu}_{3}\left(\mathrm{PO}_{4}\right)_{2} \cdot 3 \mathrm{H}_{2} \mathrm{O}$ nanoflower, $125 \mathrm{mmol} \mathrm{L}{ }^{-1} \mathrm{H}_{2} \mathrm{O}_{2}, 125 \mu \mathrm{g} \mathrm{mL}{ }^{-1} \mathrm{SC}-\mathrm{Cu}_{3}\left(\mathrm{PO}_{4}\right)_{2} \cdot 3 \mathrm{H}_{2} \mathrm{O}$ nanoflower and $125 \mathrm{mmol} \mathrm{L}^{-1} \mathrm{H}_{2} \mathrm{O}_{2}$. The reaction condition is under room temperature, reaction time is $15 \mathrm{~h}$.

$$
\begin{aligned}
& -\mathrm{d} C_{t} / \mathrm{d} t=k C_{t} \\
& \ln \left(C_{0} / C_{t}\right)=k t
\end{aligned}
$$

As we all know, oxidation is the most common method used to degrade dyes and other organic pollutants. In addition to a prompt removal of the colors, $\mathrm{OH} \cdot$ radicals was simultaneously able to fully oxidize the dyes, with a complete mineralization of carbon into $\mathrm{CO}_{2}$. Sulfur heteroatoms were converted into innocuous $\mathrm{SO}_{4}{ }^{2-}$ ions. The mineralization of nitrogen was more complex. Nitrogen atoms in the -3 oxidation state, such as in amino-groups remain at this reduction degree and produced $\mathrm{NH}_{4}{ }^{+}$cations, subsequently and very slowly converted into $\mathrm{NO}_{3}{ }^{-}$ion. The feasibility of such a degradation could be determined by varying the chemical structures. ${ }^{47}$ The degradation mechanism of the RhB mainly involved the broken of benzene ring in RhB combined with de-ethylation and hydroxylation process, ${ }^{48}$ while for $\mathrm{MB}$, it mainly involved the broken of $\mathrm{C}=\mathrm{N}, \mathrm{C}=\mathrm{S}-\mathrm{C}$ bond the $\mathrm{MB}$ central aromatic ring by $\mathrm{H}^{+} /$electron transfer followed with demethylation. ${ }^{49}$ As we know, it was more effortless to break $\mathrm{C}=\mathrm{N}$ and $\mathrm{C}=\mathrm{S}-\mathrm{C}$ bond than the benzene ring, leading to a higher degradation rate for $\mathrm{MB}$ than RhB. As for RhB and R6G which have similar structures, the difference between degradation rate may due to that $\mathrm{RhB}$ had more ethyls than R6G, which was beneficial to accelerate de-ethylation and hydroxylation process.

It is known that copper compound possess intrinsic peroxidase-like activity in the presence of $\mathrm{H}_{2} \mathrm{O}_{2}$, which has been reported by many groups. ${ }^{38,45}$ To verify the peroxidase-like activity is actually occurring in their system, A. K. Dutta et al. tested the as-prepared CuS NPs through the catalytic oxidation of a peroxidase substrate, TMB in the presence of $\mathrm{H}_{2} \mathrm{O}_{2}$. Similar to $\mathrm{Fe}^{2+}$ or $\mathrm{Fe}^{3+}$, this $\mathrm{Cu}^{2+}$ ion may acts as Fenton-like reagent and interact with the substrate in presence of hydrogen peroxide, resulting in a colored reaction product. ${ }^{45}$

The reason of the catalytic activity of $\mathrm{SC}-\mathrm{Cu}_{3}\left(\mathrm{PO}_{4}\right)_{2} \cdot 3 \mathrm{H}_{2} \mathrm{O}$ nanoflowers was associated with $\mathrm{Cu}_{3}\left(\mathrm{PO}_{4}\right)_{2} \cdot 3 \mathrm{H}_{2} \mathrm{O}$ framework while the biosurfactants were only induced the nucleation of $\mathrm{Cu}_{3}\left(\mathrm{PO}_{4}\right)_{2} \cdot 3 \mathrm{H}_{2} \mathrm{O}$ crystals to form the nanoflowers. The reaction equations are displayed as follows:

$$
\begin{aligned}
& \mathrm{Cu}^{2+}+\mathrm{H}_{2} \mathrm{O}_{2} \rightarrow \mathrm{Cu}^{1+}+\mathrm{HOO} \cdot+\mathrm{H}^{+} \\
& \mathrm{Cu}^{1+}+\mathrm{H}_{2} \mathrm{O}_{2} \rightarrow \mathrm{Cu}^{2+}+\cdot \mathrm{OH}+\mathrm{OH}^{-}
\end{aligned}
$$

In order to further investigate the influence factors of the catalytic activity, $\mathrm{MB}$ solution $\left(12.5 \mu \mathrm{g} \mathrm{mL}^{-1}\right)$ was taken as a sample to investigate the influence of concentrations of nanoflowers and $\mathrm{H}_{2} \mathrm{O}_{2}$ on dye degradation. A visible color disparity of $\mathrm{MB}$ solution was observed whether change concentration of hybrid nanoflowers (Fig. 7A) or $\mathrm{H}_{2} \mathrm{O}_{2}$ (Fig. 7B). The UV/vis absorption spectra also confirm a more thorough degradation of $\mathrm{MB}$ solutions with the higher concentration of hybrid nanoflowers or $\mathrm{H}_{2} \mathrm{O}_{2}$. What's more, the recycling experiment for the degradation of $\mathrm{MB}$ using $\mathrm{SC}-\mathrm{Cu}_{3}\left(\mathrm{PO}_{4}\right)_{2} \cdot 3 \mathrm{H}_{2} \mathrm{O}$ nanoflower $/ \mathrm{H}_{2} \mathrm{O}_{2}$ system was also taken, the degradation process was shown in Scheme 2. After 6 cycles, the nanoflowers still performed excellent catalytic activity and the final degradation rate of MB solution remained above $95 \%$ in each cycle, which indicated a stable structure and outstanding catalytic activity of our nanoflowers. The degradation rates of $\mathrm{MB}$ 

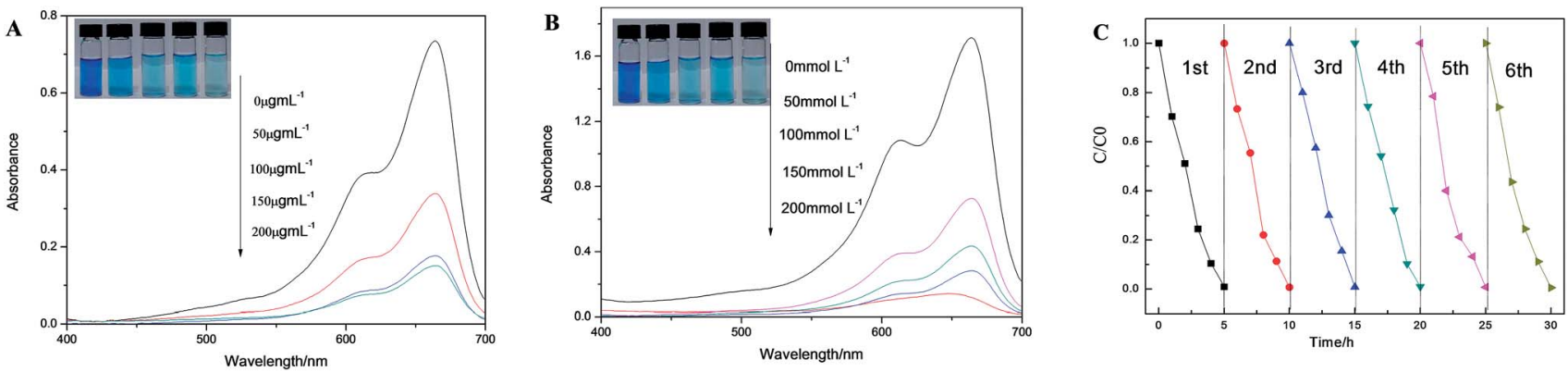

Fig. 7 (A) UV/vis absorption spectra of MB solutions containing $\mathrm{H}_{2} \mathrm{O}_{2}$ upon the addition of different concentrations of hybrid nanoflowers $\left(0-200 \mu \mathrm{g} \mathrm{m}^{-1}\right)$. (B) UV/vis absorption spectra of $\mathrm{MB}$ solutions containing hybrid nanoflowers upon the addition of different concentrations of $\mathrm{H}_{2} \mathrm{O}_{2}\left(0-200 \mathrm{mmol} \mathrm{L}^{-1}\right)$. Inset photos were the color change of the solutions. Other conditions: $12.5 \mu \mathrm{gL}^{-1} \mathrm{MB} \mathrm{solution} 125 \mu \mathrm{g} \mathrm{mL} \mathrm{L}^{-1}$ hybrid nanoflowers and reaction $15 \mathrm{~h}$ at $25^{\circ} \mathrm{C}$. (C) The first six cycling runs for degradation of $12.5 \mu \mathrm{g} \mathrm{mL}^{-1} \mathrm{MB}$ solution which contains $125 \mu \mathrm{g} \mathrm{mL}{ }^{-1}$ nanoflowers and $125 \mathrm{mmol} \mathrm{L}-1 \mathrm{H}_{2} \mathrm{O}_{2}$

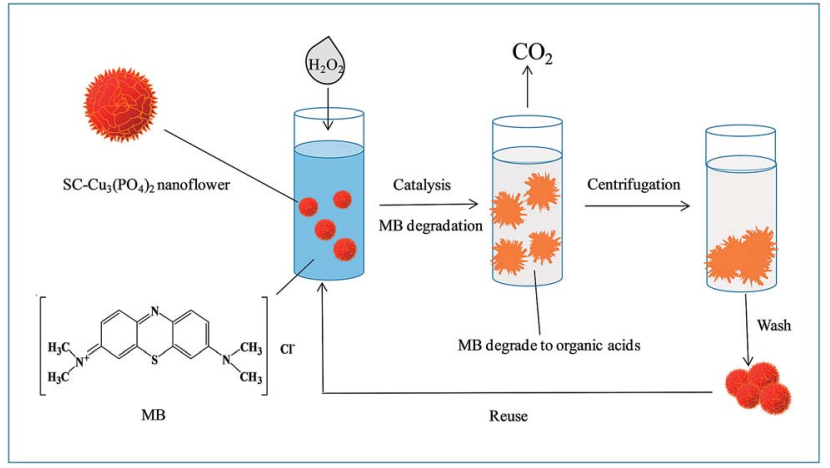

Scheme 2 The scheme of recycling of nanoflowers as an efficient catalyst for degradation of $\mathrm{MB}$

solution which contains nanoflowers and $\mathrm{H}_{2} \mathrm{O}_{2}$ for the six cycles were displayed in Fig. 7C.

\section{Conclusion}

In summary, a facile and effective self-assembled template method for low temperature synthesis of 3D flower-like $\mathrm{Cu}_{3}(-$ $\left.\mathrm{PO}_{4}\right)_{2} \cdot 3 \mathrm{H}_{2} \mathrm{O}$ microstructures through biosurfactants-assisted self-assembly with copper ions were designed. Based on the comprehensive test results and analysis, the following main conclusions are obtained. It can be concluded that the biosurfactants were particularly employed as nucleation and growth sites for deposition of copper phosphate and as structural guiding supporters to form the flower morphology. What's more, the concentration of biosurfactants and the growth time were critical to the sizes and morphologies of the hybrid nanoflowers and our $\mathrm{Cu}_{3}\left(\mathrm{PO}_{4}\right)_{2} \cdot 3 \mathrm{H}_{2} \mathrm{O}$ nanoflowers can still performed high catalytic efficiency after reused 6 times, indicating its potential as an efficient and stable catalyst for degradation of organic pollutions in waste water.

\section{Conflicts of interest}

There are no conflicts to declare.

\section{Acknowledgements}

We gratefully acknowledge the financial support from the Young Scholars Program of Shandong University (2016WLJH20).

\section{References}

1 A. Mohanty, N. Garg and R. Jin, A Universal Approach to the Synthesis of Noble Metal Nanodendrites and Their Catalytic Properties, Angew. Chem., Int. Ed., 2010, 49, 4962-4966.

2 K. Leung, S. Xuan, X. Zhu, D. Wang, C. Chak, S. Lee, W. Ho and B. Chung, Gold and iron oxide hybrid nanocomposite materials, Chem. Soc. Rev., 2012, 41, 1911-1928.

3 Z. Bai, X. Yan, Y. Li, Z. Kang, S. Cao and Y. Zhang, 3DBranched $\mathrm{ZnO} / \mathrm{CdS}$ Nanowire Arrays for Solar Water Splitting and the Service Safety Research, Nature, 2007, 447, 1098-1101.

4 Z. Hu, L. Wang, K. Zhang, J. Wang, F. Cheng, Z. Tao and J. Chen, $\mathrm{MoS}_{2}$ Nanoflowers with Expanded Interlayers as High-Performance Anodes for Sodium-Ion Batteries, Angew. Chem., Int. Ed., 2014, 53, 12794-12798.

5 C. Ma, X. Qi, B. Chen, S. Bao, Z. Yin, X. Wu, Z. Luo, J. Wei and H. Zhang, $\mathrm{MoS}_{2}$ nanoflower-decorated reduced graphene oxide paper for high-performance hydrogen evolution, Nanoscale, 2014, 6, 5624-5629.

6 J. Du, Z. Liu, Z. Li, B. Han, Z. Sun and Y. Huang, Carbon nanoflowers synthesized by a reduction-pyrolysiscatalysisroute, Mater. Lett., 2005, 59, 456-458.

7 X. Ma and B. Yuan, Fabrication of carbon nanoflowers by plasma-enhanced chemical vapor deposition, Appl. Surf. Sci., 2009, 255, 7846-7850.

8 S. Thongtem, P. Singjai, T. Thongtem and S. Preyachoti, Growth of carbon nanoflowers on glass slides using sparked iron as a catalyst, Mater. Sci. Eng. A, 2006, 423, 209-213.

9 J. Bian, S. Shu, J. Li, C. Huang, Y. Li and R. Zhang, Reproducible and recyclable SERS substrates: Flower-like $\mathrm{Ag}$ structures with concave surfaces formed by electrodeposition, Appl. Surf. Sci., 2015, 333, 126-133. 
10 Z. Wang, J. Zhang, J. M. Ekman, J. A. Kenis and Y. Lu, DNAMediated Control of Metal Nanoparticle Shape: One-Pot Synthesis and Cellular Uptake of Highly Stable and Functional Gold Nanoflowers, Nano Lett., 2010, 10, 18861891.

11 S. Cha, C. Mo, K. Kim and S. Hong, Ferromagnetic cobalt nanodots, nanorices, nanowires and nanoflowers by polyol process, J. Mater. Res., 2005, 20, 2148-2153.

12 L. Liu, J. Guan, W. Shi, Z. Sun and J. Zhao, Facile Synthesis and Growth Mechanism of Flower like Ni-Fe Alloy Nanostructures, J. Phys. Chem. C, 2010, 114, 13565-13570.

13 D. Bin, B. Yang, K. Zhang, C. Wang, J. Wang, J. Zhong, Y. Feng, J. Guo and Y. Du, Design of PdAg Hollow Nanoflowers through Galvanic Replacement and Their Application for Ethanol Electrooxidation, Chem. - Eur. J., 2016, 22, 16642-16647.

14 S. Kim, J. Lee, H. Ahn, H. Song and J. Jang, Facile Route to an Efficient NiO Supercapacitor with a Three Dimensional Nanonetwork Morphology, ACS Appl. Mater. Interfaces, 2013, 5, 1596-1603.

$15 \mathrm{H}$. Heli and A. Rahi, Synthesis and Applications of Nanoflowers, Recent Pat. Nanotechnol., 2016, 10, 86-115.

16 B. I. Kharisov, A Review for Synthesis of Nanoflowers, Recent Pat. Nanotechnol., 2008, 2, 190-200.

17 M. Zeng, Y. Li, F. Liu, Y. Yang, M. Mao and X. Zhao, Cu doped OL-1 nanoflower: A UV-vis-infrared light-driven catalyst for gas-phase environmental purification with very high efficiency, Appl. Catal., B, 2017, 200, 521-529.

18 S. K. Arya, S. Saha, J. E. Ramirez-Vick, V. Gupta, S. Bhansali and S. P. Singh, Recent advances in ZnO nanostructures and thin films for biosensor applications: Review, Anal. Chim. Acta, 2012, 737, 1-21.

19 K. Huang, Y. Liu, Y. Liu and L. Wang, Molybdenum disulfide nanoflower-chitosan-Au nanoparticles composites based electrochemical sensing platform for bisphenol A determination, J. Hazard. Mater., 2014, 276, 207-215.

$20 \mathrm{~S}$. He, C. Hu, H. Hou and W. Chen, Ultrathin $\mathrm{MnO}_{2}$ nanosheets supported on cellulose based carbon papers for high-power supercapacitors, J. Power Sources, 2014, 246, 754-761.

21 D. Wang, Z. Pan, Z. Wu, Z. Wang and Z. Liu, Hydrothermal synthesis of $\mathrm{MoS}_{2}$ nanoflowers as highly efficient hydrogen evolution reaction catalysts, J. Power Sources, 2014, 264, 229-234.

22 Y. Liu, Y. Jiao, Z. Zhang, F. Qu, A. Umar and X. Wu, Hierarchical $\mathrm{SnO}_{2}$ Nanostructures Made of Intermingled Ultrathin Nanosheets for Environmental Remediation, Smart Gas Sensor, and Supercapacitor Applications, ACS Appl. Mater. Interfaces, 2014, 6, 2174-2184.

$23 \mathrm{~L}$. $\mathrm{Hu}, \mathrm{Y}$. Ren, H. Yang and Q. Xu, Fabrication of 3D Hierarchical $\mathrm{MoS}_{2} /$ Polyaniline and $\mathrm{MoS}_{2} / \mathrm{C}$ Architectures for Lithium-Ion Battery Applications, ACS Appl. Mater. Interfaces, 2014, 6, 14644-14652.

24 W. Yang, Z. Gao, J. Wang, J. Ma, M. Zhang and L. Liu, Solvothermal One-Step Synthesis of Ni-Al Layered Double Hydroxide/Carbon Nanotube/Reduced Graphene Oxide Sheet Ternary Nanocomposite with Ultrahigh Capacitance for Supercapacitors, ACS Appl. Mater. Interfaces, 2013, 5, 5443-5454.
25 Y. Huang, X. Ran, Y. Lin, J. Ren and X. Qu, Self-assembly of an organic-inorganic hybrid nanoflower as an efficient biomimetic catalyst for self-activated tandem reactions, Chem. Commun., 2015, 51, 4386-4389.

$26 \mathrm{Y}$. Xu and W. Zhang, Morphology-controlled synthesis of $\mathrm{Ag}_{3} \mathrm{PO}_{4}$ microcrystals for high performance photocatalysis, CrystEngComm, 2013, 15, 5407-5411.

27 H. Yao, H. Fang, X. Wang and S. Yu, Hierarchical assembly of micro-/nano-building blocks:bio-inspired rigid structural functional materials, Chem.Soc.Rev., 2011, 40, 3764-3785.

28 N. Xiao and B. J. Venton, Rapid sensitive detection of neurotransmitters at microelectrodes modified with selfassembled SWCNT forests, Anal. Chem., 2012, 84, 7816-7822.

29 G. Zan and Q. Wu, Biomimetic and Bioinspired Synthesis of Nanomaterials/Nanostructures, Adv. Mater., 2016, 28, 20992147.

30 Z. Zhang, X. Kong, K. Xiao, G. Xie, Q. Liu, Y. Tian, H. Zhang, J. Ma, L. Wen and L. Jiang, A Bioinspired Multifunctional Heterogeneous Membrane with Ultrahigh Ionic Rectification and Highly Efficient Selective Ionic Gating, Adv. Mater., 2016, 28, 144-150.

31 S. S. Nadar, S. D. Gawas and V. K. Rathod, Self-assembled organic-inorganic hybrid glucoamylase nanoflowers with enhanced activity and stability, Int. J. Biol. Macromol., 2016, 92, 660-669.

32 C. Altinkaynak, S. Tavlasoglu, N. Özdemir and I. Ocsoy, A new generation approach in enzyme immobilization: Organic-inorganic hybrid nanoflowers with enhanced catalytic activity and stability, Enzyme Microb. Technol., 2016, 93, 105-112.

33 Z. Lin, Y. Xiao, Y. Yin, W. Hu, W. Liu and H. Yang, Facile Synthesis of Enzyme-Inorganic Hybrid Nanoflowers and Its Application as a Colorimetric Platform for Visual Detection of Hydrogen Peroxide and Phenol, ACS Appl. Mater. Interfaces, 2014, 6, 10775-10782.

34 J. Sun, J. Ge, W. Liu, M. Lan, H. Zhang, P. Wang, Y. Wang and Z. Niu, Multi-enzyme co-embedded organic-inorganic hybrid nanoflowers: synthesis and application as a colorimetric sensor, Nanoscale, 2014, 6, 255-262.

35 Z. Lin, Y. Xiao, L. Wang, Y. Yin, J. Zheng, H. Yang and G. Chen, Facile synthesis of enzyme-inorganic hybrid nanoflowers and their application as an immobilized trypsin reactor for highly efficient protein digestion, $R S C$ Adv., 2014, 4, 13888-13891.

36 Y. Yin, Y. Xiao, G. Lin, Q. Xiao, Z. Lin and Z. Cai, An enzymeinorganic hybrid nanoflower based immobilized enzyme reactor with enhanced enzymatic activity, J. Mater. Chem. $B, 2015,3,2295-2300$.

37 K. Kim, J. Jeong, S. Lee, B. Choi and K. Lee, Protein-directed assembly of cobalt phosphate hybrid nanoflowers, J. Colloid Interface Sci., 2016, 484, 44-50.

38 Z. Wu, Z. Wang, Y. Zhang, Y. Ma, C. He, H. Li, L. Chen, Q. Huo, L. Wang and Z. Li, Amino acids-incorporated nanoflowers with an intrinsic peroxidase-like activity, Sci. Rep., 2016, 6, 22412.

39 J. Ge, J. Lei and R. N. Zare, Protein-Inorganic Hybrid Nanoflowers, Nat. Nanotechnol., 2012, 7, 428-432. 
40 L. Wang, Y. Wang, R. He, A. Zhuang, X. Wang, J. Zeng and J. Hou, A New Nanobiocatalytic System Based on Allosteric Effect with Dramatically Enhanced Enzymatic Performance, J. Am. Chem. Soc., 2013, 135, 1272-1275.

41 Y. Qiao, Y. Lin, Y. Wang, Z. Yang, J. Liu, J. Zhou, Y. Yan and J. Huang, Hierarchical Self-Assembled One-Dimensional Nanohelices, Nano Lett., 2009, 9, 4500-4504.

42 Y. Qiao, Y. Wang, Z. Yang, Y. Lin and J. Huang, SelfTemplating of Metal-Driven Supramolecular Self-Assembly: A General Approach toward 1D Inorganic Nanotubes, Chem. Mater., 2011, 23, 1182-1187.

43 Q. Wang, W. Li and J. Shi, Biomolecule-assisted route for shape-controlled synthesis of $3 \mathrm{D}$ flower-like $\mathrm{CdWO}_{4}$ microstructures, RSC Adv., 2015, 5, 61330-61336.

44 B. Zhang, X. Ye, W. Hou, Y. Zhao and Y. Xie, BiomoleculeAssisted Synthesis and Electrochemical Hydrogen Storage of $\mathrm{Bi}_{2} \mathrm{~S}_{3}$ Flowerlike Patterns with Well-Aligned Nanorods, $J$. Phys. Chem. B, 2006, 110, 8978-8985.
45 A. K. Dutta, S. Das, S. Samanta, P. K. Samanta, B. Adhikary and P. Biswas, Nanoparticles as a mimic peroxidase for colorimetric estimation of human blood glucose level, Talanta, 2013, 107, 361-367.

46 W. P. Kwan and B. M. Volker, Rates of Hydroxyl Radical Generation and Organic Compound Oxidation in MineralCatalyzed Fenton-like Systems, Environ. Sci. Technol., 2003, 37, 1150-1158.

47 H. Lachhe, E. Puzenat and A. Houas, Photocatalytic degradation of various types of dyes (Alizarin S, Crocein Orange G, methyl red, congo red, methylene blue) in water by UV-irradiated titania, Appl. Catal., B, 2002, 39, 75-90.

48 H. Liu, T. Peng, Z. Peng and K. Dai, Photocatalytic Degradation Mechanism of RhB over Dy-Doped $\mathrm{WO}_{3}$ Photocatalysts, Wuhan Univ. J. Nat. Sci., 2007, 2, 127-132.

$49 \mathrm{Z}$. Yu and S. C. Chuang, Probing Methylene Blue Photocatalytic Degradation by Adsorbed Ethanol with In Situ IR, J. Phys. Chem. C, 2007, 111, 13813-13820. 